\title{
REFLEXIÓN SOBRE LA ENSEÑANZA DE CAMBIOS EN EL COMPORTAMIENTO PARA LA PREVENCIÓN BÁSICA DEL COVID- 19
}

Actualmente se reportan aproximadamente a nivel mundial 27.6 millones de casos y un estimado de 898,000 muertes por COVID - 19. En El Salvador las cifras también son altas 26,602 casos y 775 muertes $^{2}$.Por su parte, las Universidades como Instituciones de Educación Superior (IES) tienen responsabilidad social y, además, como parte de sus funciones sustantivas deben promover espacios reflexivos para crear una cultura preventiva y de promoción de la salud.Es así que la información sobre nuevas características de la fisiopatología de la infección por este virus, diariamente arrojan nuevos datos que con los días se reafirman o descartan. De igual manera surgen continuamente mitos en relación con su propagación y formas de prevención: «Las mascarillas quirúrgicas u otras como las N-95 provocan intoxicación por dióxido de carbono o falta de oxígeno» (las mascarillas N95 debidamente aprobadas por organismos reguladores tales como el Instituto Nacional de Seguridad y Salud Ocupacional (NIOSH) ajustadas al rostro de manera adecuada pueden proteger contra aerosoles que se liberan al hablar o toser, pero no dificultan la respiración de oxigeno) ${ }^{3}$, «El calor detiene la propagación del virus» (si bien el calor reduce la sobrevivencia del virus, el calor ambiental en sí mismo no protege de su infección en las condiciones adecuadas para que dicha infección persona a persona sea efectiva), «Las redes móviles $5 \mathrm{G}$ propagan el virus», «La hidroxicloroquina y la cloroquina son tratamientos efectivos contra el COVID-19» (hasta ahora solo se ha demostrado que este medicamento es efectivo para tratar la malaria e incluso para algunas enfermedades auto inmunes, pero no para tratar esta infección viral), «El virus fue creado o se liberó accidentalmente de un laboratorio» (cuando en realidad la información disponible trata de una zoonosis), «Las lámparas ultravioletas son más efectiva para eliminar el virus que lavarse las manos con jabón y agua o aplicarse geles desinfectantes a base de alcohol» (las lámparas ultravioleta pueden causar daños en la vista o en la piel) ${ }^{4}$.

Las anteriores aseveraciones generan dos interrogantes principales: ¿cómo asegurar la asimilación de conocimientos, actitudes y prácticas correctas en relación con la prevención de la infección por este virus? y ¿cómo se da el proceso de enseñanza - aprendizaje de prácticas correctas de manera sostenible, es decir: cómo aprendemos?

En primer lugar, obviamente la información (conocimiento) que se provea debe estar sustentado en evidencia la cual puede ser avalada por instancias de salud internacional como la Organización Mundial de la Salud (OMS), el Centro para el Control de Enfermedades (CDC) reforzado con estudios locales.

1 Vicerrector Investigación y Proyección Social Máster Salud Pública, máster Medicina Internacional y Salud Tropical, posgrado en Calidad en Salud https://orcid.org/0000-0002-0394-1178 
Según Gordon Guyatt la medicina basada en la evidencia se define como un proceso cuyo objetivo es

el de obtener y aplicar la mejor evidencia científica en el ejercicio de la práctica médica cotidiana ${ }^{5}$. Y el proceso de enseñanza aprendizaje debe sustentarse en técnicas efectivas que aseguren cambios de comportamiento.

Es importante proveer información sobre el papel que juega la transmisibilidad del agente patógeno, la susceptibilidad del huésped y el análisis causal; en este caso, de las causas «necesarias» que son aquellos factores que pueden o no estar presentes para determinar la infección, posterior enfermedad y las causas suficientes que son aquellas que de manera imprescindible deben estar presentes para que ocurra la trasmisión del agente. La trasmisión de un mensaje efectivo también debe considerar aspectos culturales, sociales y valores de la población meta ${ }^{6}$.

Existen diferentes teorías sociales, psicológicas y andragógicas con enfoques y perspectivas complementarias de cómo aprendemos, cómo pasamos de estar informados a cambiar nuestro comportamiento o conductas que se pueden aplicar al campo de la educación y promoción de la salud en el caso del COVID - 19. Las teorías que se p resentan a continuación son perspectivas que deben integrarse, tomándose lo más relevante de cada una:

1. Fases para el cambio

2. Aprendizaje social

3. Mercadeo o marketing social

4. Modelo de cambio de comportamiento - comunicación

5. Modelo unificado ${ }^{7}$.

\section{Fases para el cambio}

Se considera que en términos generales las personas suelen recorrer una serie de fases $(5$ o 6 según diferentes autores) para adoptar un nuevo comportamiento (en el caso de la enfermedad COVID-19 se puede retomar el uso consistente de mascarilla facial, distanciamiento social, uso de alcohol gel y lavado de manos, entre otros)

1. Pre-contemplación: la persona ni siquiera es consiente que debe cambiar, no tiene noción, por ejemplo, del riesgo de no usar mascarilla ni de la necesidad de su uso.

2. Contemplación: el cambio se empieza a valorar como una posibilidad, se esbozan aspectos positivos y negativos del uso de mascarilla.

3. Preparación: existe una intención o decisión ya asumida de cambiar o adoptar un hábito, se decide por el uso de la mascarilla o se compran dichas mascarillas. 
4. Acción: se practican acciones concretas, como el uso de mascarilla: ya llevamos un par de días usándola.

5. Mantenimiento: el hábito adoptado se mantiene de manera permanente (adherencia de manera sostenida al cambio de al menos un mes).

6. Recaída: regresamos al viejo hábito abandonado como no usar mascarilla, esto se puede dar en la fase de acción o en la de mantenimiento ${ }^{8}$.

\section{Aprendizaje social}

A nivel individual

Se basa en que existe un conjunto de aspectos claves sobre los que deben incidirse. Están conformados por el huésped (sujeto del cambio), su actitud o creencias correctas y anuentes en relación con el cambio, sujeción a comportamientos sustentables y el medio ambiente social y físico que debe ser reforzado.

Debe existir un «grupo social de referencia el cual debe valorar positivamente un determinado comportamiento y censurar su falta. Dentro de este grupo social podríamos incluir modelos pares y consejeros (evitar por ejemplo rodearse de personas «negacionistas» (que niegan la existencia del virus) o «conformistas» (que consideran que de algo hay que morirse).

Según esta propuesta las personas tienden a adoptar con más facilidad nuevos comportamientos si estos son novedosos, llamativos, fáciles de conocer, analizar e interpretar de manera voluntaria.

También se retoma lo expuestos por otras teorías, enfatizando la importancia de contar con el apoyo de líderes comunitarios de referencia que asuman los comportamientos de manera inicial conociéndose como «adoptadores precoces».

Los resultados positivos (recompensas evidenciables) o beneficios de un determinado comportamiento deben socializarse: mostrar por ejemplo estadísticas de las personas que usan mascarillas tienden a contraer menos el virus y la importancia de reducir la carga viral inoculada. Se espera que haya motivadores individuales y de grupo a pequeña y gran escala simultáneamente. También, se pueden utilizar elementos que desalientan un comportamiento como el uso de infracciones o multas.

En general, las personas retoman nuevos comportamientos cuando ve que otras personas ya los han adoptado de manera exitosa. Es un tipo de aprendizaje observacional que ocurre cuando una persona nota que otras reciben beneficios, recompensas y respaldo por cierto comportamiento.

A nivel grupal

La planificación y aplicación de un programa social para el cambio implica:

1. Diagnóstico de la situación actual en torno al comportamiento promovido (que incluya determinación de causas personales, sociales, políticas, institucionales que han determinado el comportamiento que se desea superar: falta de uso consistente de mascarilla o distanciamiento social). 
2. Fijar una meta (\% de la población que usará mascarillas o usar la mascarilla en el 100\% de las veces que la persona sale de su casa).

3. Diseñar diferentes estrategias de mensajes y vías de trasmisión (uso de redes sociales, televisión, radio, entrega de panfletos para dar a conocer y adquirir el tipo de mascarillas que ofrecen mayor protección, forma de uso adecuado, determinar si se reutilizará o no, cada cuánto se esterilizará, si fuesen reutilizables cuidados generales de su uso, colocar las mascarillas en un lugar estratégico accesible de la casa).

4. Seleccionar la estrategia más efectiva para alcanzar la meta propuesta (tipo de lenguaje entendible para la población diana, definir el tipo de mascarilla más efectiva, regular su precio en farmacia, dar a conocer establecimientos de entrega; diseñar y enseñar rutina de uso (protocolo personal de uso), poner en práctica técnicas de colocación y retiro de mascarillas.).

5. Estandarizar el mensaje y la estrategia que resultó más exitosa, adaptándolas a diferentes poblaciones según sus características.

\section{Mercadeo o marketing social}

Implica retomar aspectos o elementos exitosos propuestos por el mercadeo social. El mercadeo social propone diferentes elementos básicos interactuantes para la adquisición de un comportamiento:

1. Producto: son los bienes, servicios o comportamientos que se desea promover.

2. Precio: es lo que se debe «pagar» o el costo personal y social (costo de oportunidad) por un servicio, bien o la adquisición de un comportamiento determinado. El precio o costo de adquirir un comportamiento debe ser accesible (precios bajos y ofertas para la compra de mascarillas, dar ítems para hacer su uso más cómodo, falta de costumbre, reducir los peligros del anonimato social al cubrirse el rostro).

3. Distribución o plaza: son los lugares físicos o establecimientos donde estarán disponibles el servicio, bien o insumos que se requieran para el comportamiento que se espera adquirir (farmacias, establecimientos de salud).

4. Promoción: son las características del mensaje que debe presentarse como atractivo e innovador y los medios de mayor difusión y efectividad posibles (radio, televisión, redes sociales, periódicos digitales o impresos). El mensaje debe considerar aspectos geográficos, demográficos (grupos etarios, sexo de la población); nivel de organización y estructuración comunitaria y social (lugares de trabajo, escuelas, instituciones religiosas, grupos de voluntarios, gobiernos locales). 


\section{Modelos de cambio de comportamiento-comunicación}

Este modelo plantea y refuerza la necesidad que se tiene para la promoción y adquisición de un determinado comportamiento de una serie de elementos:

1. Concientización: hacer sensibles a las personas, introyectar la noción de riesgos para su salud que no implica el uso de mascarillas o distanciamiento social.

2. Medios: seleccionar la población meta y los medios de comunicación más adecuados.

3. Motivación: dar a conocer los beneficios de los cambios adquiridos, incentivos sociales y públicos que «premien» estas conductas.

4. Información o conocimientos básicos: que es lo más importante que debe conocerse, aspectos epidemiológicos (definición de caso y contacto), generalidades de la prevención del COVID- 19.

5. Cambio de actitud: implica de procesos de diálogo, reflexión y acercamiento permanente a la población meta.

6. Competencias y práctica: se debe entrenar mediante demostraciones y prácticas a las personas para que aprendan nuevas habilidades y comportamientos.

7. Mantenimiento: se deben realizar actividades permanentes de retroalimentación que consoliden los comportamientos adquiridos, evitando que estos se olviden o deformen.

\section{Modelo unificado}

Esta es el modelo que al autor de este artículo le parece más adecuado. Esta perspectiva propone una combinación de las diferentes teorías, técnicas o modelos de enseñanza-aprendizaje antes expuestos (se combinan los aspectos claves propuestos en los modelos de fases para el cambio, aprendizaje social, mercadeo o marketing social y el modelo de cambio de comportamiento - comunicación.

En conclusión, se puede afirmar que este modelo unificado es el que proponemos aplicar en el caso de la promoción de la salud y cambio de comportamiento relacionado con el COVID-19, pues es más integral y estructurado a partir de diferentes enfoques o perspectivas.

2 https://www.google.com/search?q=casos+covid+el+salvador\&oq=casos+covid+el+salvador\&aqs=chrome.69i57.6207j0j4\&sourceid=c hrome\&ie=UTF-8

3 https://www.massgeneral.org/es/coronavirus/la-diferencia-entre-las-mascarillas-N95-las-mascarillas-quirurgicas-y-las-mascarillas-de-tela

4 Centro de Información sobre el coronavirus (COVID - 19), Organización Mundial de la Salud (OMS)

5 Medicina basada en la evidencia (MBE). Ventajas Rev Esp Cirug Oral y Maxilofac vol.25 no.5 Madrid sep. /oct. 2003, http://scielo.isciii.es/ scielo.php?script=sci_arttext\&pid=\$1130-05582003000500003

6 https://blogs.worldbank.org/es/voices/coronavirus-reflexiones-de-un-epidemiologo-y-profesional-de-la-salud-publica

7 https://www.scielosp.org/article/rpsp/1998.v4n2/142-148/es/

8 https://www.psicoglobal.com/blog/cambiar-habitos-etapas-cambio 